\title{
Survival Status and Its Predictors Among Adult Human Immunodeficiency Virus Infected Patients Attending Their Antiretroviral Treatment at Health Centers in Kirkos Sub City, Addis Ababa, Ethiopia. A Retrospective Cohort Study
}

Selam Tesfayohannes Amha

Sisay Moges ( $\square$ sisaymoges55@gmail.com )

Hosanna Health science college https://orcid.org/0000-0002-3400-972X

Sisay Shine

Abinet Dagnaw

Research

Keywords: Survival, Mortality, ART, HIV/AIDS, Predictors, health center, Ethiopia

Posted Date: November 2nd, 2020

DOI: https://doi.org/10.21203/rs.3.rs-99601/v1

License: (c) (1) This work is licensed under a Creative Commons Attribution 4.0 International License.

Read Full License 


\section{Abstract}

\section{Background}

Burden of HIV/AIDS is high in low- and middle-income countries including Ethiopia. In resource-poor countries like Ethiopia, the survival of patients with AIDS treated with ART depends on a variety of factors, which may also vary greatly with economic, demographic, behavioral risk, and health factors. Unlike other previous studies, this study was done at health centers since some of the clinical factors may differently affect the survival of the patients under ART.

\section{Objectives}

The main aim of this study is to estimate the mortality rate and survival predictors among adult HIV infected patients under ART at health centers in Kirkos sub city.

\section{Method}

A retrospective cohort study was conducted at the health centers found in Kirkos sub-city, Addis Ababa. All adult HIV positive patients under follow-up between Dec. 1, 2014, and Oct. 30, 2019 were the source population. A total of 665 samples were taken using the lottery method. Data were extracted from the patient card and electronic database by trained data collectors. Kaplan-Meier and Cox-proportional hazard regressions were used.

Result

a total of 55(8.5\%) of death has occurred with the incidence death of 3.25/100 person-years. Majority of deaths occurring within 6 months of ART initiation. Predictors mortality were patients with age category above 50 years $(\mathrm{AHR}=4.90,95 \% \mathrm{Cl}: 2.00,11.98)$, TB comorbidity $(\mathrm{AHR}=3.46,95 \% \mathrm{Cl}: 1.52,7.91), \mathrm{WHO}$ stage IV (AHR $=4.55,95 \% \mathrm{Cl}: 1.72,12.02)$, lack of dug adherence $(\mathrm{AHR}=1.76,95 \% \mathrm{Cl}: 1.23,3.33)$, cotrimoxazole therapy (AHR=2.56, 95\% Cl: 1.25,5.24),BMl of less than 18.5 (AHR=2.59, 95\% Cl: 1.37,4.90) and CD4 cell count, below 200/dl (AHR $=22.77,95 \% \mathrm{Cl}: 1.30,5.92)$.

\section{Conclusion}

The majority of deaths occurring within six months of ART initiation. Factors directly or indirectly affects immunity were associated with poor survival. Prevention of TB infection, enhancing feeding and early screening of nutritional status of patients' needs great attention.

\section{Background}

Human immunodeficiency viruses (HIV) is one of the global and regional burdens of public health. Globally, nearly 1.7 million people are newly infected by HIV. And approximately 770,000 deaths reported in 2018 and 32.0 million people have died from acquired immunodeficiency syndrome (AIDS)-related 
illnesses since the start of the epidemic [1], [2]. People living with HIV/AIDS now live longer and healthier lives due to the greater availability of antiretroviral (ART) treatment. Moreover, where ART treatment is readily available, HIV/AIDS morbidity has shown a modest reduction. However, the mortality and morbidity are still higher in developing country including Ethiopia [3]. In Ethiopia, various activities have been done to improve the health quality of HIV-positive patients, quality of life, and extend the time interval from HIV-infection/AIDS-diagnosis to death [4]. However, around 11,000 people die from HIV related illness in Ethiopia [5].

The risk of mortality among patients with HIV/AIDS is approximately 5 times higher in patients with AIDS than in HIV-infected Patients without AIDS. Risk factors for excess mortality include a viral load greater than 400 Copies/mL, CD 4 count less than 200 cells/mL, and cytomegalovirus retinitis[6]. Other contributing factors for mortality from HIV related illness were TB co-infection, WHO clinical stage, ART regimen, drug allergy, ART regimen change, and, hemoglobin level [7].

However, these factors are not the only factors that contribute to mortality of HIV/AIDS; also, several other factors could affect the survival of the HIV patients under ART follow-up are varies among different areas and there are also institutional variations; also different studies reported different factors. Furthermore, most of the studies done in Ethiopia were based on the medical records in hospitals; there are only a few studies done on health center-based medical records. Thus, in health centers, some of the clinical factors may differently affect the survival of the patients under ART. Therefore, this study is important to generate evidence on mortality and survival predictors of HIV infected patients under ART in the health centers.

\section{Methods And Materials}

\section{Study design, and setting}

A retrospective cohort study design was conducted to estimate mortality rate and its predictors among adult HIV positive patients who had been on ART follow-up. A study was done in health centers at Kirkos sub-city, Addis Ababa Ethiopia. Kirkos sub-city is one of the 10 sub-cities in Addis Ababa and located in the city center. According to the 2011 estimate, the total population in the sub-city was 235,441 . There are a total of 7 health centers in Kirkos sub-city. ART clinic is one of the departments in the health centers which provide services for HIV/AIDS patients. The study was conducted on health centers in Kirkos subcity from January 2014 to October 2019

\section{Study population and sampling}

All adult HIV positive patients on ART who have complete registration, intake, and follow-up forms in the selected health centers were included in the study. The sample size is calculated by using Epi-info, Version 7 considering tuberculosis (TB) co-infection which gives highest sample among several factors, a hazard-ratio (HR) of 2.9 and the percentage of outcome among unexposed was 3.1\% [8], 95\% level of confidence and $80 \%$ power, the computed sample size was 577 . After adding $15 \%$ for the incomplete 
medical records, the final sample size required for this study is 665 . In this study, three health centers were randomly selected using the lottery method from seven health center found at Kirkos sub city. Then, study participants were selected proportionally from each of the three health centers based on the number of patients on the follow-up using a simple random sampling method. A schematic explanation is presented below in the Fig. 1

\section{Data collection method and tool}

The selected health centers ART registration and follow up formats were the source of data and data was collected using a checklist which is prepared in English language after reviewing national registration book content and different kinds of literatures [7], [9]-[11], and it is designed to incorporate information extracted from electronic and paper-based ART registration and follow-up forms of the ART clinic.

\section{Study variables}

The dependent variable was time to death and divided as death (event) and censored outcomes which measured in months. Censored means Patients who were alive at the end of follow up (the 30th of October 2019) or lost-to-follow-up (transferred out).

The predictors include demographic characteristics: (age, sex, educational level, marital status, religion); Clinical characteristics: (Active TB during ART, Baseline weight, WHO clinical stage, CD4 count and Baseline hemoglobin and baseline BMl; and Treatment) and follow up related factors such as: ART regimen, drug allergy, Functional status, ART regimen change, drug adherence and co-trimoxazole therapy.

\section{Data processing and Analysis:}

Data entered using Epi-Data version 3.1 and analysis was conducted by SPSS version 20 and STATA version 14.1. Descriptive statistics was used to summarize the characteristics of the cohort. Kaplan-Meier (KM) estimates and Log-rank tests were used to compare survival curves among the variables with categories. Both bivariate and multivariable Cox-proportional hazard model was also employed after checking the assumption of proportionality using Global test using STATA and both crude and adjusted Hazard Ratios were estimated. The result was presented by using texts, tables, charts, and graphs.

\section{Result}

\section{Social-demographic characteristics of the participants}

A total of $665 \mathrm{HIV}$ infected adult patients were included in this study with and 52 were excluded due to incomplete medical record. Of these, 329 (53.7\%) were females. The mean age was 38.65 (SD \pm 10.32$)$ years and more than half $320(52.2 \%)$ of participants age was $35-50$ years and the majority $(96.7 \%)$ were urban residents. Regarding educational level, 195 (32.3\%) attended primary (1-8) education, More than half $(52.6 \%)$ of the patients were daily laborer and majority $(50.8 \%)$ were single and majority $(62.3 \%)$ were orthodox religious followers (Table 1). 
Table 1

Socio-demographic characteristics of patients under ART in Health canters at Kirkos sub-city Addis Ababa, Ethiopia, 2014-2019.

\begin{tabular}{|c|c|c|}
\hline Variables & Frequency & Percentage \\
\hline \multicolumn{3}{|l|}{ Sex } \\
\hline Male & 284 & 46.3 \\
\hline Female & 329 & 53.7 \\
\hline Age category(years) mean $( \pm$ SD) & $38.65( \pm 10.32)$ & \\
\hline $17-34$ & 219 & 35.7 \\
\hline $35-50$ & 320 & 52.2 \\
\hline$>50$ & 74 & 12.1 \\
\hline \multicolumn{3}{|l|}{ Residence } \\
\hline Urban & 593 & 96.7 \\
\hline Rural & 16 & 2.6 \\
\hline \multicolumn{3}{|l|}{ Educational level } \\
\hline No education & 166 & 27.5 \\
\hline Primary education & 195 & 32.3 \\
\hline Secondary education & 187 & 31.0 \\
\hline Tertiary education & 56 & 9.3 \\
\hline \multicolumn{3}{|l|}{ Occupation } \\
\hline Formal employee(Gov't/NGO) & 177 & 29.1 \\
\hline Daily laborer & 320 & 52.6 \\
\hline Farmer/housewife & 111 & 18.3 \\
\hline Formal employee(Gov't/NGO) & 177 & 29.1 \\
\hline \multicolumn{3}{|l|}{ Marital status } \\
\hline Single & 310 & 50.6 \\
\hline Married & 158 & 25.8 \\
\hline Widowed & 55 & 9.0 \\
\hline Divorced & 90 & 14.7 \\
\hline Religion & & \\
\hline
\end{tabular}




\begin{tabular}{|l|lll|}
\hline Variables & Frequency & Percentage \\
\hline Protestant & 92 & 15.0 \\
\hline Orthodox & 382 & 62.3 \\
& Muslim & 117 & 19.1 \\
\hline & Others (catholic, Adventists, only Jesus,) & 17 & 2.8 \\
\hline \multirow{2}{*}{ Clinical and follow up characteristics }
\end{tabular}

The baseline mean hemoglobin was $13.41 \mathrm{~g} / \mathrm{dl}(\mathrm{SD}= \pm 3.01)$. Among the total participants, $143(23.3 \%)$ had active TB during treatment and about $277(45.2 \%)$ of the patients were at WHO clinical stage I and 97(15.8\%) at WHO clinical stage IV. And majority (89.1\%) of the patients on ART follow-up had a CD4 + count of $\geq 200$ (cells/ $\mu \mathrm{l}$ ). Majority $(61.3 \%)$ of participants had drug allergy and most $(74.4 \%)$ of the participants had drug adherence. Around $428(69 \%)$ had BMI of above 18.5 and majority $(79.6 \%)$ of the adult HIV-infected patients were recommended TDF + 3TC + EFV regimen at the initiation of the follow-up. Concerning Co-trimoxazole therapy, more than half $(57.1 \%)$ have not received Co-trimoxazole therapy (Table 2). 
Table 2

Clinical characteristics of patients under ART in Health centres at Kirkos sub-city Addis Ababa, Ethiopia, 2014-2019.

\begin{tabular}{|c|c|c|}
\hline Variables & Frequency & Percentage \\
\hline Baseline hemoglobin(g/dl) mean ( \pm SD) & $13.25( \pm 3.16)$ & \\
\hline$<10$ & 33 & 5.4 \\
\hline$\geq 10$ & 577 & 94.6 \\
\hline \multicolumn{3}{|l|}{ Active TB during treatment } \\
\hline No & 470 & 76.7 \\
\hline Yes & 143 & 23.3 \\
\hline \multicolumn{3}{|l|}{ WHO clinical stages } \\
\hline Stage I & 277 & 45.2 \\
\hline Stage II & 145 & 23.7 \\
\hline Stage III & 94 & 15.3 \\
\hline Stage IV & 97 & 15.8 \\
\hline Base line CD4+ (cells/ $\mu \mathrm{l})$ mean $( \pm S D)(n=613)$ & $391.2( \pm 143.5)$ & \\
\hline$<200$ & 67 & 10.9 \\
\hline$\geq 200$ & 546 & 89.1 \\
\hline \multicolumn{3}{|l|}{ Functional status } \\
\hline Working & 401 & 65.4 \\
\hline Ambulatory & 168 & 27.4 \\
\hline Bedridden & 44 & 7.2 \\
\hline \multicolumn{3}{|l|}{ Drug allergy } \\
\hline No & 376 & 61.3 \\
\hline Yes & 237 & 38.7 \\
\hline \multicolumn{3}{|l|}{ Drug adherence } \\
\hline No & 157 & 25.6 \\
\hline Yes & 456 & 74.4 \\
\hline \multicolumn{3}{|l|}{ Body mass index } \\
\hline$<18.5$ & 183 & 29.9 \\
\hline
\end{tabular}




\begin{tabular}{|lll|}
\hline Variables & Frequency & Percentage \\
\hline$\geq 18.5$ & 428 & 69.8 \\
\hline Baseline ART regimen & & \\
ABC + 3TC + EFV & 96 & 15.7 \\
TDF-3TC-EFV & 488 & 79.6 \\
\hline Others & 29 & 4.7 \\
Change in the ART regimen from baseline & & \\
\hline No & 531 & 86.6 \\
Yes & 82 & 13.4 \\
Co-trimoxazole therapy & & 57.1 \\
\hline No & 350 & 42.7 \\
\hline Yes & 262 & \\
\hline
\end{tabular}

\section{Mortality and Survival analysis}

The cohort contributed a total of 1,693 person-years of follow up and the overall median follow-up time was 34 months (interquartile range, 33 months). Among 613 adult HIV infected patients under follow up, $55(8.5 \%)$ were died giving an incidence death rate of 3.25 per 100 person-years, 51 (8.3\%) were lost to follow up, 44(7.2\%) were transferred out to other ART centers, and 463 (88.6\%) were alive at by the $31 \mathrm{st}$ December 2019. Among 55 patients died, 11(20\%) died within 3 months after the start of treatment (Fig. 2). And the mean survival duration was 62.35 months, $95 \% \mathrm{Cl},(60.87$, and 63.84). Kaplan-Meier survival estimation showed that overall estimated survival duration after ART initiation was 68.27 months. (Fig. 3).

\section{Predictors of HIV mortality among adult patients:}

In bivariate cox proportional regression analysis, age of participants, occupation, marital status of widowed, and divorced, Active TB status, WHO clinical stage, Functional status, Co-trimoxazole therapy, $\mathrm{BMI}, \mathrm{CD} 4+$ counts and baseline hemoglobin level $<10$, were considered as potential confounders and included in the multivariate cox proportional model.

In multivariate model, assumption of the Cox proportional model called test of proportional-hazards assumption based on Schoenfeld residual (Phtest) was checked using a global test with the value of chi ${ }^{2}$ $(21)=31, P=0.073$. Thus, the assumption is met since the $p$-value is greater than 0.05 . Then, after conducting bi-variable for each predictor, all variables with $p$-value $\leq 0.2$ and known confounders were entered into multivariable cox proportional hazard regression model. In multivariate cox proportional hazard regression analysis, Age, active TB, WHO clinical staging, baseline functional status, cotrimoxazole therapy, baseline BMI, and, baseline CD4 + count were independent predictors of mortality in 
the adjusted Cox regression model. However, drug allergy, drug adherence, baseline ART regimen baseline hemoglobin level, and change in ART regimen were not associated with mortality. (Table 3 )

Adult HIV Patients with age category above 50 years have a 4.89 times higher hazard of death as compared to $17-34$ years. (AHR $=4.90,95 \% \mathrm{Cl}: 2.00,11.98)$. Patients with TB comorbidity was highly associated with an increased risk of mortality; thus, the hazard of death was 3.46 times higher than without active tuberculosis (AHR $=3.46,95 \% \mathrm{Cl}: 1.52,7.91)$. And Patients at WHO stage IV were at increased risk of death as compared to their counterparts (stage I) (AHR $=4.55,95 \% \mathrm{Cl}: 1.72,12.02)$. Regarding functional status, bedridden patient was 2.6 times than the risk for ambulatory patients (AHR $=2.89,95 \% \mathrm{Cl}: 1.26,6.60, \mathrm{P}=0.012$ ). And drug adherence was also significantly associated with mortality. Thus, patients who were reported with lack of drug adherence have a greater hazard of death $A H R=1.76$, $95 \% \mathrm{Cl}: 1.23,3.33)$. Taking co-trimoxazole therapy decreased the risk of death by $61 \%$. There was 2.56 times the risk of death for patients not taking co-trimoxazole therapy. $\mathrm{AHR}=2.56,95 \% \mathrm{Cl}: 1.25,5.24, \mathrm{P}=$ 0.01). Patients with a BMI of less than 18.5 had a greater hazard of death as compared to its counterpart $(A H R=2.59,95 \% \mathrm{Cl}: 1.37,4.90)$. And patients with a CD4 cell count, below 200/ul, had a 2.7-fold higher risk of mortality (AHR $=22.77,95 \% \mathrm{Cl}: 1.30,5.92)$ than individuals with $\mathrm{CD} 4$ count $\geq 200 / \mathrm{ul}$ after controlling for other factors. (Table 3) 
Table 3

Summary of bivariate and multivariate Cox- proportional regression analysis on predictors of mortality among adult patients under ART in Health centres at Kirkos sub-city Addis Ababa, Ethiopia, 2014-2019. (Note: $* P=0.01-0.05, * \star P<0.01$ )

\begin{tabular}{|c|c|c|c|c|}
\hline \multirow[t]{2}{*}{ Variable } & \multicolumn{2}{|c|}{ Survival status } & \multirow[t]{2}{*}{$\mathrm{CHR}(95 \% \mathrm{Cl})$} & \multirow[t]{2}{*}{$\operatorname{AHR}(95 \% \mathrm{Cl})$} \\
\hline & Censored & Died & & \\
\hline \multicolumn{5}{|l|}{ Age } \\
\hline $17-34$ & 210 & 9 & 1 & \\
\hline $35-50$ & 298 & 22 & $1.67(0.76,3.62)$ & $2.07(0.90,4.79)$ \\
\hline$>50$ & 49 & 25 & $10.48(4.88,22.55)^{\star \star}$ & $4.89(2.00,11.98)^{\star \star}$ \\
\hline \multicolumn{5}{|l|}{ Occupation } \\
\hline Formal employee(Gov't/NGO) & 168 & 9 & 1 & \\
\hline daily laborer & 292 & 28 & $1.69(0.80,3.59)$ & $1.72(0.74,3.98)$ \\
\hline Farmer/housewife & 93 & 18 & $3.47(1.56,7.74)^{\star}$ & $1.41(0.55,3.64)$ \\
\hline \multicolumn{5}{|l|}{ Marital status } \\
\hline Single & 293 & 17 & 1 & \\
\hline Married & 145 & 13 & $1.63(0.7953 .37)$ & $1.75(0.73,4.17)$ \\
\hline Widowed & 44 & 11 & $3.96(1.85,8.477)^{\star \star}$ & $0.92(0.31,2.72)$ \\
\hline Divorced & 76 & 14 & $3.06(1.51,6.21)^{\star \star}$ & $1.79(0.75,4.24)$ \\
\hline \multicolumn{5}{|l|}{ Active TB status } \\
\hline No & 455 & 15 & 1 & 1 \\
\hline Yes & 103 & 40 & $8.54(4.78,15.25)^{\star \star}$ & $3.46(1.52 .7 .91)^{\star \star}$ \\
\hline \multicolumn{5}{|l|}{ WHO clinical staging } \\
\hline stage I & 271 & 6 & 1 & 1 \\
\hline stage II & 140 & 5 & $1.27(0.40,4.01)$ & $0.43(0.11,1.59)$ \\
\hline stage III & 79 & 15 & $6.73(2.74,16.52)^{\star \star}$ & $1.78(0.57,5.56)$ \\
\hline Stage IV & 68 & 29 & $14.64(6.40,33.49)^{\star \star}$ & $4.55(1.72,12.02)^{\star \star}$ \\
\hline \multicolumn{5}{|l|}{ Functional status } \\
\hline Working & 381 & 20 & 1 & 1 \\
\hline Ambulatory & 155 & 13 & $1.40(0.70,2.81)$ & $0.96(0.423,2.197$ \\
\hline Bedridden & 22 & 22 & $11.56(6.33,21.11)^{\star \star}$ & $2.89(1.26,6.60) *$ \\
\hline
\end{tabular}




\begin{tabular}{|c|c|c|c|c|}
\hline \multirow[t]{2}{*}{ Variable } & \multicolumn{2}{|c|}{ Survival status } & \multirow[t]{2}{*}{$\mathrm{CHR}(95 \% \mathrm{Cl})$} & \multirow[t]{2}{*}{$\operatorname{AHR}(95 \% \mathrm{Cl})$} \\
\hline & Censored & Died & & \\
\hline \multicolumn{5}{|c|}{ Drug allergy } \\
\hline No & 355 & 21 & 1 & 1 \\
\hline Yes & 203 & 34 & $2.50(0.46,4.28)$ & $0.95(0.46,1.95)$ \\
\hline \multicolumn{5}{|c|}{ Drug adherence } \\
\hline Yes & 425 & 31 & 1 & 1 \\
\hline No & 133 & 24 & $2.16(1.27,3.67)$ & $1.76(1.23,3.33)^{\star}$ \\
\hline \multicolumn{5}{|c|}{ Co-trimoxazole therapy } \\
\hline No & 308 & 42 & $2.30(1.25,4.22)^{*}$ & $2.56(1.25,5.24)^{*}$ \\
\hline Yes & 248 & 14 & 1 & 1 \\
\hline \multicolumn{5}{|l|}{ BMI } \\
\hline$<18.5$ & 151 & 32 & $3.11(1.83,5.28)^{\star}$ & $2.59(1.37,4.90)^{\star \star}$ \\
\hline$\geq 18.5$ & 405 & 23 & 1 & \\
\hline \multicolumn{5}{|c|}{ CD $4^{+}$counts } \\
\hline$<200 /$ ul & 39 & 28 & $9.012(5.33,15.22) *$ & $2.77(1.30,5.92) *$ \\
\hline$\geq 200 / \mathrm{ul}$ & 518 & 28 & 1 & \\
\hline \multicolumn{5}{|c|}{ Baseline hemoglobin } \\
\hline$<10$ & 15 & 18 & $12.09(6.86,21.31)^{\star}$ & $0.612(0.28,1.33)$ \\
\hline$\geq 10$ & 540 & 37 & 1 & 1 \\
\hline
\end{tabular}

\section{Discussion}

In this study, the mortality of patients enrolled on ART, and factors that predict mortality of patients under ART follow up was assessed. Among 613 adult HIV infected patients under follow up, 55(8.5\%) were died giving an incidence death rate of 3.25 per 100 person-years, Similar finding was reported from a study done at Aksum hospital, northern Ethiopia in which overall mortality rate of 3.2 per 100 person-years [9]. And lower than studies done in Addis Ababa, Ethiopia, the mortality incidence was 3.8/100 person-years, 3.9 per 100 mperson year in Harar, Ethiopia and another higher mortality rate of $10.3 \%$; 5.4 deaths/100 person-years was reported from a study done at seven universities based on national ART follow-up data and 3.4 deaths per 100 person-years in Dilla [10], [12]-[14]. And present study finding is higher than study findings done in southern Ethiopia 2.03 per 100 person-years [7], eastern Ethiopia 1.89 deaths per 100 
person-years [15], and study done in Uganda[16]. The reason for such difference could be due to differences in study setting or difference due to the difference in the quality of care and service provision.

And in this study, the majority of (46\%) of death occurred within 6 months of their follow up and $11(20 \%)$ died within the first 3 months. A consistent finding was demonstrated in a hospital-based retrospective study in western Ethiopia. According to the study, most of the deaths (60\%) were within the first 6 months [15]. And another multi-site prospective cohort study done in Ethiopia also revealed that seventy percent of the deaths occurred within six months of starting ART [12]. But in some other studies, the majority of deaths occurring within three months of starting ART [12], [14], [17]. The reason could be the fact that usually HIV patients come to institution after advanced clinical stage and at early time, lack of drug adherence could contribute to high mortality.

Regarding predictors of mortality, age, active TB, WHO clinical staging, baseline functional status, cotrimoxazole therapy, baseline $\mathrm{BMI}$, and, baseline $\mathrm{CD} 4+$ count were independent predictors of mortality in the adjusted Cox regression model.

In the present study, patients with age category above 50 years have a 4.89 times higher hazard of death as compared to 17-34 years. A consistent finding was reported from previous studies done in Uganda [16] and western Ethiopia [15]. The reason could be the fact that old age is associated with immunologic suppression, exposure to infectious diseases, psychosocial comorbidities, and the other factors of disease progression. But, it was not reported as a significant predictor in studies done in other parts of Ethiopia [18], [19]. This could be because of the predominantly young age of patients and study setting and sample difference.

A study done in Uganda revealed that being male increases the risk of mortality, as well as single marital status was related to a higher risk of HIV mortality [16]. And sex, educational status, and marital status of the Patients were reported as a significant predictor in studies done in Ethiopia [17], [19]. However, there was no significant difference in sex, educational status, and marital status of the participant in our study; which is in agreement with the study done at Fiche Hospital in North Shao, Oromia. education, sex, and marital status were not reported as significant predictors [18]. And a similar finding was reported from other studies done in Ethiopia, including a study done in Zewditu hospital in Addis Ababa [7], [10]-[12], [14], [20].

In the present study, it is demonstrated that Patients with TB comorbidity was highly associated with an increased risk of mortality and the hazard of death among patients with TB comorbidity was 3.46 times higher than without active tuberculosis. A consistent finding was reported from another similar investigation from Ethiopia, And the risk of death for patients who lived with tuberculosis was about 2.872-fold times higher than those patients who were negative also reported from a study done on two hospitals and six health centers at Illubabor and Buno Bedele zone [11]. and report from Uganda showed that mortality from TB co-infection was 1.81 times higher [16]. And based on a research report from eastern Ethiopia, TB co-infection at baseline or later was also associated with increased risk of mortality 
[17].A similar finding was reported from other studies [8], [18]. The reason is the fact that TB co-infection lowers the immunity of the patient.

Advanced WHO clinical stages (stage IV) have been consistently reported as risk factors for mortality in several studies from Ethiopia [12], [13], [17], [19] this study demonstrated similar finding thus, WHO stage IV were at increased risk of death as compared to their counterparts (stage I) and the hazard of death was 4.1 times higher. ART should be started (initiated) as early as possible, before advanced clinical stages. Mortality among patients with AIDS was nearly halved in the HAART era but remains approximately 5 times higher in patients with AIDS than in HIV-infected Patients without AIDS [6]. And this study demonstrated that drug adherence as a significant predictor of mortality. A study done in western Ethiopia revealed similar findings in which non adherent participants had a mortality of 42.5 deaths per 100 person-years and were two times as likely to die as adherent participants [15]. Another similar study also reported consistent findings (19). Some of the similar previous cohort studies demonstrated that higher CD4 cell count would reduce morbidity and mortality [17]-[19]. This study found that patients whose CD4 cell count $<200$ cells/ mm3 had a higher risk of death compared to patients with a CD 4 cell count $\geq 500$ cells $/ \mathrm{mm} 3$. The study showed that the CD 4 cell count was an independent predictor of AIDS progression, and was also consistent with the other research results done outside of Ethiopia [21], [22] which indicated that AIDS progression to death was clustered among patients starting therapy with a lower CD4 cell count. Thus, emphasizing the need to early diagnose, link, and engage patient into the comprehensive ART care program.

Another important independent predictor of mortality identified in the current study was baseline BMI. Patients with $\mathrm{BMI}<18.5 \mathrm{~kg} / \mathrm{m}^{2}$ had greater hazard of death as compared to $\geq 18.5 \mathrm{~kg} / \mathrm{m}^{2}$ and a consistent finding was reported from a study in Somalia. Thus, the risk of death in patients with a BMI < $18.5 \mathrm{Kg} / \mathrm{m} 2$ was more than two times higher compared $\geq 18.5 \mathrm{~kg} / \mathrm{m}^{2}$ [17]. Also, another study conducted in Cameroon showed that $\mathrm{BMI}<15 \mathrm{~kg} / \mathrm{m}^{2}$ had a three times higher risk of death than $\mathrm{BMI}>18.5 \mathrm{~kg} / \mathrm{m}$. [23]. This could be due to malnutrition suppress the immunity and result of the aggregate effects of malnutrition-induced immune system dysfunction, a higher burden of opportunistic infections, metabolic derangement and anthropometric variations [24]

In the present study, Adult HIV-infected patients who were bedridden at ART initiation had a higher risk of mortality compared to the patients with working functional status at treatment initiation. the finding is consistent with a study done in Eastern Ethiopia [17], southern Ethiopia [10], and those described elsewhere [19], [25], [26]. However, it was not reported as a significant predictor in a study done in western Ethiopia [15].

Co-trimoxazole is a feasible, well-tolerated, and inexpensive intervention for people living with HIV to reduce HIV- related morbidity and mortality [27]. However, the current study demonstrated not taking cotrimoxazole prophylaxis was significantly associated with mortality. Thus, patients who had not taken have 2.56 times higher risk of death compared to its counterpart. A consistent result was demonstrated from a study done in Harar, Ethiopia. Thus, not taking cotrimoxazole Prophylaxis Treatment (CPT) at the 
baseline has a higher risk of death [13]. The finding was also in line with the study done in Uganda [16] and other parts of Ethiopia [7].

\section{Limitation of the study}

Even though incomplete and missing data was minimized by cross checking electronic data base and patients medical record, due to retrospective nature of the data, selection bias is possibly introduced because patients with incomplete records of variables were excluded. And for those patients lost to follow-up, mortality results might be an underestimation because the status of the patient's status cannot be known.

\section{Conclusion}

This study showed that the incidence of death was 3.25/100 person-years with the majority of deaths occurring within six months of ART initiation. Advanced age, CD 4 + count of below 200 copies/ul, advanced clinical staging, functional status (Bedridden), BMI lower than 18.5, No co-trimoxazole therapy, and poor ART adherence were associated with higher risk of death among adult HIV/AIDS patients under HAART. Longitudinal clinical and CD4 cell count monitoring to facilitate active initiation of ART and enhancing feeding habit and early screening of nutritional status and multiple comorbidities among HIV positive patients needs great attention.

\section{Abbreviations}

AIDS: acquired immune deficiency syndrome;

AOR: Adjusted odds ratio

ART: Antiretroviral therapy

CD4: Cluster of differentiation 4

COR: Crude odds ratio

HIV: Human immunodeficiency virus

TB: Tuberculosis;

\section{Declarations}

\section{Ethics approval and consent to participate}

Ethical clearance was obtained from the Ethical Review Committee of Debre Berhan University. Permission letter was also obtained from the selected Health Centers. All collected data were kept 


\section{Consent for publication}

Not applicable

\section{Availability of data and materials}

If needed, the raw data in excel format for this article is available

\section{Competing Interests}

The authors declare that they have no competing interests.

\section{Authors' Contributions}

ST contributed in the generation of the topic, preparation of proposal, data collection and analysis. SM contributed in reviewing the proposal, data analysis and assisted in development of the manuscript, SS \& AD contributed in critically reviewing proposal, data analysis and the manuscript. All authors read and approved the final manuscript.

\section{Funding}

The study is not funded.

\section{References}

[1] World Health Organizaion (WHO), "Global statics and WHO HIV statics," WHO, 2018.

[2] World Health Organization(WHO), "Global health observatory (GHO) data," 2018.

http://www.who.intghochild_healthmortalityneonatal_texten.

[3] United Nations Program on AIDS (UNAIDS) and UNAIDS, "Press release/ right to health report," Cape town/Geneva, 2017.

[4] FHAPCO, "HIV prevention in ethiopia national road map 2018-2020." FHAPCO, Ethiopia, 2018.

[5] United Nation Program on AIDS (UNAIDS), "HIV countries report/ Ethiopia (www.unaids.org/en/regionscountries/countries/ethiopia)," 2019. 
[6] S. Croxford, A. Kitching, and S. Desai, "Mortality and causes of death in people diagnosed with HIV in the era of highly active antiretroviral therapy compared with the general population: Analysis of a national observational cohort," Lancet Public Heal., 2017.

[7] T. Yohannis, S. Moges, and T. Laelago, "Survival Analysis of Adult Human Immune Virus Infected Patients under Antiretroviral Treatment at Wachemo University Nigist Ellen Mohammed Memorial Hospital, Southern Ethiopia," Int. J. Intern. Med. Geriatr., pp. 21-32, 2019.

[8] K. Kebebew and E. Wencheko, "Survival analysis of HIV-infected patients under antiretroviral treatment at the Armed Forces General Teaching Hospital, Addis Ababa, Ethiopia," Ethiop. J. Heal. Dev., vol. 26, no. 3, 2012.

[9] K. Tadesse, F. Haile, and N. Hiruy, "Predictors of Mortality among Patients Enrolled on Antiretroviral Therapy in Aksum Hospital , Northern Ethiopia: A Retrospective Cohort Study," vol. 9, no. 1, 2014, doi: 10.1371/journal.pone.0087392.

[10] S. Hailemariam, "Determinants of Survival in HIV Patients: A Retrospective Study of Dilla University Hospital HIV Cohort," Int. J. Virol. AIDS, vol. 3, 2016, doi: 10.23937/2469-567X/1510023.

[11] M. Tadege, "Time to death predictors of HIV / AIDS infected patients on antiretroviral therapy in Ethiopia," BMC Res. Notes, pp. 1-6, 2018, doi: 10.1186/s13104-018-3863-y.

[12] D. Fekade et al., "Predictors of Survival among Adult Ethiopian Patients in the National ART Program at Seven University Teaching Hospitals: A Prospective Cohort Study," Ethiop J Heal. Sci, vol. 27, no. Suppl 1, pp. 63-71, 2017, doi: 10.4314/ejhs.v27i1.7s.

[13] T. Digaffe, B. Seyoum, and L. Oljirra, “Journal of Tropical Diseases Survival and Predictors of Mortality among Adults on Antiretroviral Therapy in Selected Public Hospitals in Harar , Eastern Ethiopia," vol. 2, no. 5, 2014, doi: 10.4172/2329-891X.1000148.

[14] S. Mengesha, B. Belayihun, and A. Kumie, "Predictors of Survival in HIV-Infected Patient after Initiation of HAART in Zewditu Memorial Hospital , Addis Ababa , Ethiopia," vol. 2014, 2014, doi: 10.1155/2014/250913.

[15] M. T. Hambisa, A. Ali, and Y. Dessie, "Determinants of Mortality among HIV Positives after Initiating Antiretroviral Therapy in Western Ethiopia: A Hospital-Based Retrospective Cohort Study," vol. 2013, 2013.

[16] J. Rubaihayo et al., "Trends and Predictors of Mortality Among HIV Positive Patients in the Era of Highly Active Antiretroviral Therapy in Uganda," Infect Dis Rep, vol. 7, no. 3, p. 5967, 2015, doi: 10.4081/idr.2015.5967.

[17] B. Damtew, B. Mengistie, and T. Alemayehu, "Survival and determinants of mortality in adult HIV/Aids patients initiating antiretroviral therapy in Somali Region, Eastern Ethiopia," Pan Afr Med J, vol. 22, p. 138, 2015, doi: 10.11604/pamj.2015.22.138.4352. 
[18] K. Tesfamariam, N. Baraki, and H. Kedir, "Pre - ART nutritional status and its association with mortality in adult patients enrolled on ART at Fiche Hospital in North Shoa, Oromia region , Ethiopia: a retrospective cohort study," BMC Res. Notes, pp. 1-9, 2016, doi: 10.1186/s13104-016-2313-y.

[19] M. W. Demissie, "Statistical modeling for survival HIV/ADIS patients treated with highly active anti retro-viral treatment(HAART) :A case study at dilchora hospital. diredawa, Ethiopia ," Jouranal biometrics Biostat., vol. 9, no. 5, p. 416, 2018.

[20] E. Tachbele and G. Ameni, "Survival and predictors of mortality among human immunodeficiency virus patients on anti-retroviral treatment at Jinka Hospital, South Omo, Ethiopia: a six years retrospective cohort study," pp. 1-10, 2016.

[21] H. N. Luma et al., "Mortality in Hospitalised HIV / AIDS Patients in a Tertiary Centre in Sub-Saharan Africa: Trends Between 2007 and 2015 , Causes and Associated Factors," pp. 162-173, 2018, doi: $10.2174 / 1874613601812010162$.

[22] G. Zhang et al., "Outcomes and factors associated with survival of patients with HIV/AIDS initiating antiretroviral treatment in Liangshan Prefecture, southwest of China: A retrospective cohort study from 2005 to 2013," Medicine (Baltimore)., vol. 95, no. 27, pp. e3969-e3969, 2016, doi:

10.1097/MD.0000000000003969.

[23] P. K. Ndombo et al., "A cohort analysis of neonatal hospital mortality rate and predictors of neonatal mortality in a sub-urban hospital of Cameroon," Ital. J. Pediatr., vol. 43, no. 1, pp. 1-8, 2017, doi: 10.1186/s13052-017-0369-5.

[24] World Health Organizaion (WHO), "Antiretroviral therapy for HIV infection in adults and adolescents," 2014.

[25] Biadgilign S, R. AA, and Digaffe T, "Predictors of mortality among HIV infected patients taking antiretroviral treatment in Ethiopia: a retrospec- tive cohort study.," AIDS Res Ther., vol. 9, no. 1, p. 15, 2012.

[26] Tegiste A and Eshetu W, "Survival analysis of patients under chronic HIV-care and antiretroviral treatment at Tikur Anbessa Specialized Hospital, Addis Ababa, Ethiopia.," Ethiop. J. Heal. Dev. J Heal. Dev., vol. 26, no. 1, pp. 22-9, 2012.

[27] Federal Minster of Health (FMOH), "National consolidated guidelines for comprehensive HIV prevention, care and treatment," 2018.

\section{Figures}




\section{Sample selection procedure}



Figure 1

Schematic sampling procedure, kirkos sub city, Addis Ababa, 2020. Note: HC = health center 


\section{Outcome status of HIV/ AIDS patients under follow-up}

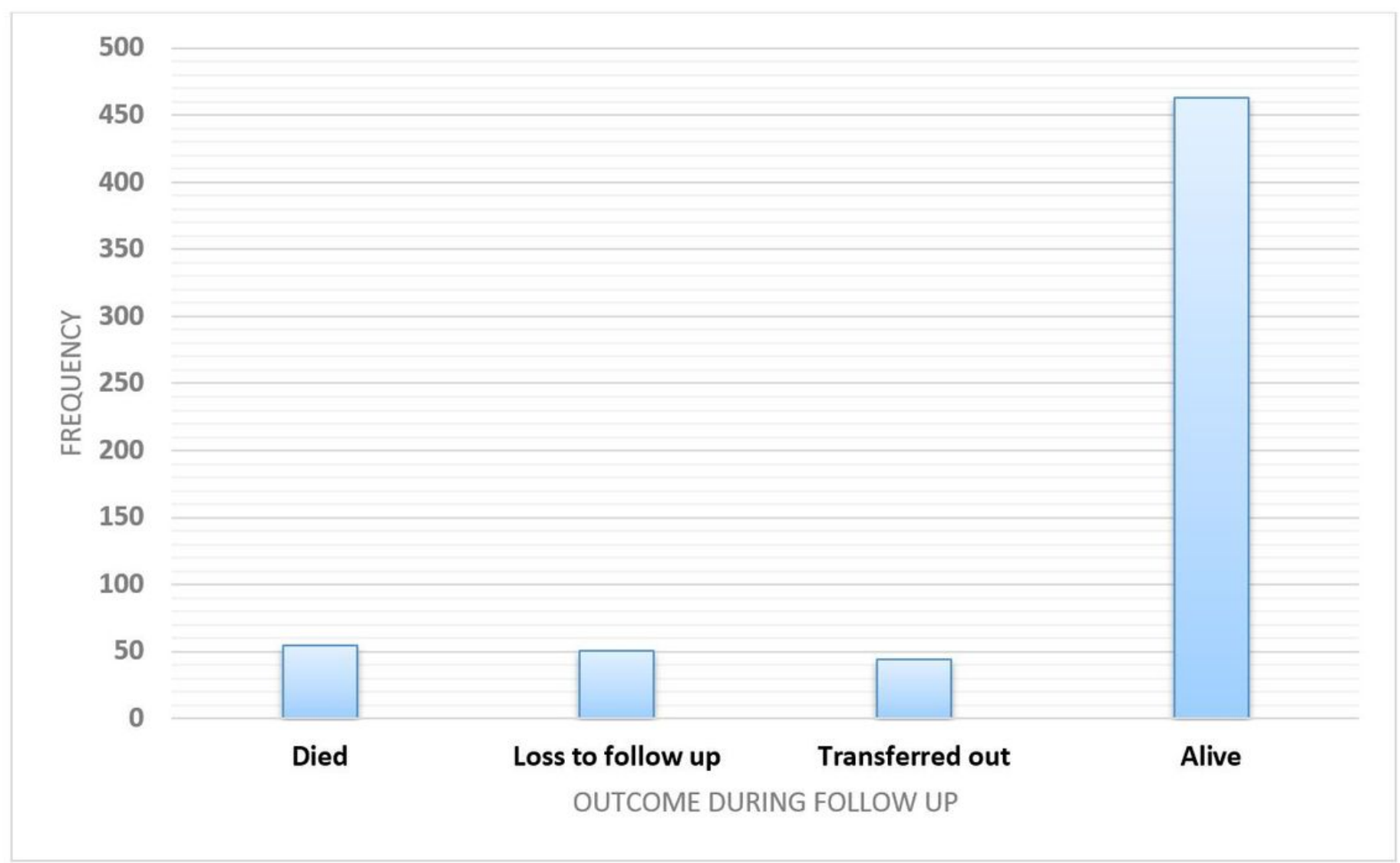

Figure 2

Adult HIV infected patients under ART follow up in Health centres at Kirkos sub-city Addis Ababa, Ethiopia, 2014-2019. 


\section{Kaplan-meier survival status of HIV/AIDS patients under follow up}

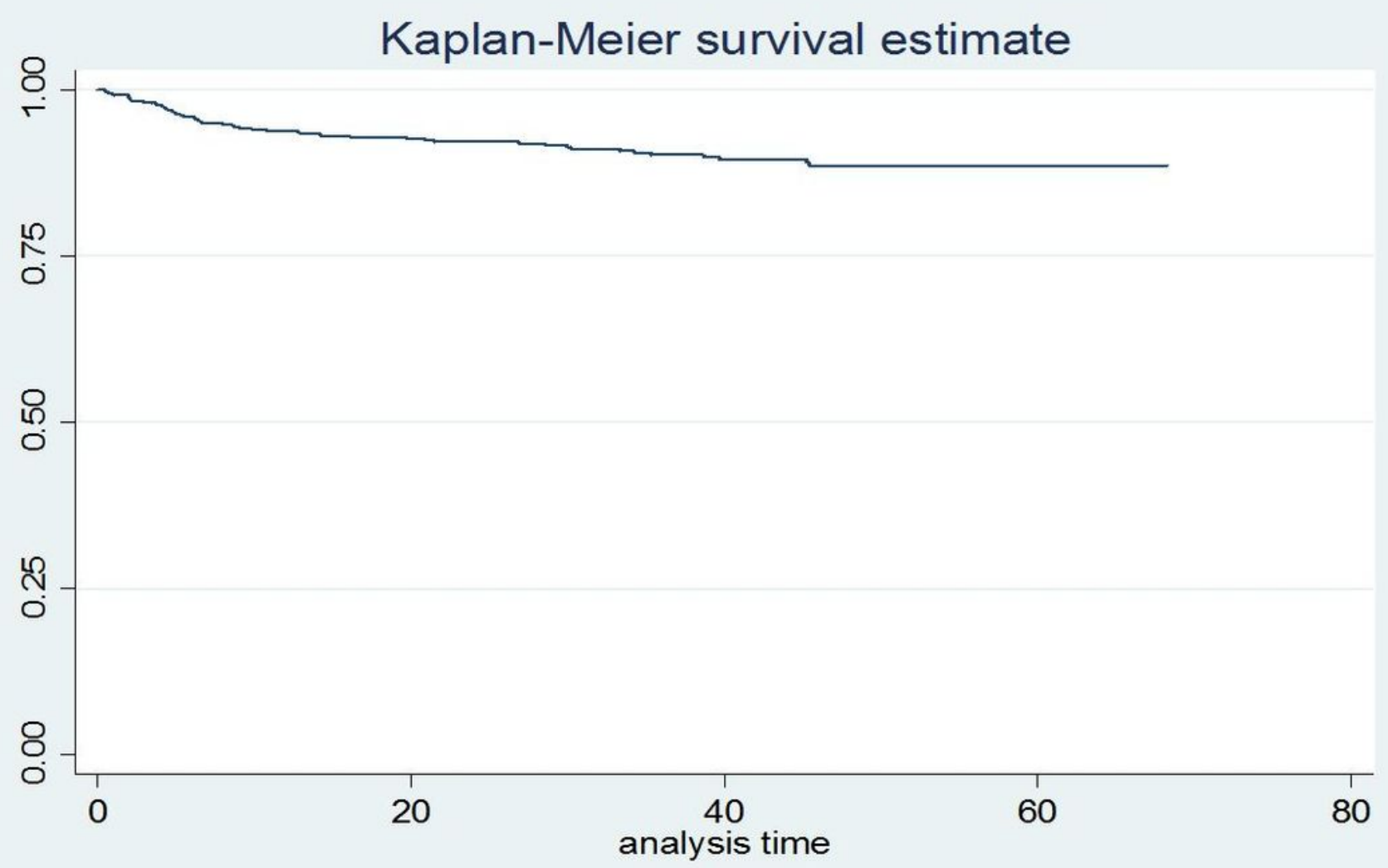

Figure 3

Kaplan-Meier survival curve of Adult HIV infected patients under ART follow up in Health centres at Kirkos sub-city Addis Ababa, Ethiopia, 2014-2019 